\title{
Estudo anatômico do lenho de Bixa arborea Huber (1)
}

\author{
Lourdes Cobra Fedalto $\left(^{2}\right)$
}

\begin{abstract}
Resumo
Análise microscópica realizada em amostras de madeira de Bixa arborea Huber. da familia Bixaceae, revelou a ocorrência de uma estrutura radial não exclusivamènte parenquimatosa. Tal fenômeno é equivalente a apenas três outros casos registrados na literatura revisada, para espécies de Angiospermae. A pesquisa evidenciou também a presença de elementos vasculares axiais, não integrantes de linhas vasculares definidas. Este trabalho documenta e descreve o lenho dessa espécie, dando enfoque às estruturas anormais observadas.
\end{abstract}

\section{INTRODUÇÃo}

Este trabalho, iniciou-se como parte de um estudo de caracterização global de espécies amazônicas, desenvoivido no Laboratório de Produtos Florestais, em Brasília. Entre as madeiras então analisadas, incluia-se a de Bixa srborea Huber, uma das poucas espécies pertencentes à família Bixaceae, e ao seu único gênero, Bixa Linn. (Metcalfe \& Chalk, 1950). No exame das amostras de algumas árvores, notaram-se detalhes anatômicos incomuns, tidos como próprios, apenas, de espécies de Gymnospermae. Diante da singularidade do que foi visto, decidiu-se proceder a um estudo mais pormenorizado, até onde as amostras disponíveis o permitissem.

A observação de um determinado tipo de estrutura característica de um grupo vegetal definido, em indivíduos não pertencentes àquele grupo, pode ter conotação com o grau evolutivo da espécie a que pertençam tais indivícuos e ser de importância para a compreensão de problemas relacionados com a filogenia da família, onde o fenômeno estiver ocorrendo.
Assim, a divulgação desses resultados, fornece subsídios para um conhecimento maior da Bixaceae.

\section{REVISÃo BIBLIOGRÁFICA}

Esau $(1972,1974)$ afirma que traqueóide radial é uma característica exclusiva das Gymnospermae e refere sua presença normal na maioria das Pinaceae e ocasional em Sequoia e nas Cupressaceae.

Jane (1970), menciona três raríssimas exceções, com relação à composição parenquimatosa dos raios das Angiospermae: são a ocorrência de traqueóides radiais em Quercus alba L. ("white oak") e em Gonioma kamassi E. Meyer, e a de fibrotraqueóides nos raios de Neesia altissima Blume. Esse autor considera que estas são as únicas anormalidades conhecidas, com relação ao assunto.

Metcalfe \& Chalk (1950), estudando anatomicamente a família Bixaceae limitam suas observações a Bixa orellana L. e não fazem referência a fenômeno incomum, ligado à estrutura radial e axial dessa espécie.

\section{MATERIAL}

As amostras de madeira de 10 árvores, utilizadas neste trabalho, procedentes da região do rio Tapajós, próxima a Belterra - rodovia Cuiabá/Santarém, encontram-se arquivadas na xiloteca e laminário do Setor de Anatomia e Morfologia da Madeira do Laboratório de Produtos Florestais, em Brasília, com os seguintes números de coleta:

(1) - Trabalho de pesquisa subvencionado pelo IBDF, PNUD e FAO, desenvolvido no Setor de Anatomia e Mor-

- fologia de Madeira do Laboratório de Produtos Florestais do Instituto Brasileiro de Desenvolvimento Florestal, em Brasilia.

(2) - Laboratório de Produtos Florestais/DE/IBDF. 
Col.: Pessoal do LPF

n's. : 0048; 0077; 0112; 0205; 0217; 0265; 0288; 0336; 0441; 0472.

A identificação botânica, com base em material coletado das mesmas árvores de oncie foram retiradas as amostras de madeira, foi efetuada parte no Herbário do Instituto Nacional de Pesquisas da Amazônia - INPA, em Manaus, e parte do Herbário do Centro de Pesquisa Agropecuária do Trópico Úmido CPATU/EMBRAPA, em Belém, onde se encontram depositadas as exsicatas.

\section{MÉTodos}

Os dados descritivos resultantes do exame de preparações histológicas de dez individuos e as classificações das diferentes estruturas anatômicas, foram obtidos conforme os critérios estabelecidos pelas Normas COPANT $(1973)^{3}$ e a partir dos dados numéricos registrados na Ficha Biométrica, decorrentes do total de aferições realizadas em dois indivíduos (Pessoal do LPF 0048; 0205).

\section{PREPARO DE AMOSTRAS E MICROTÉCNICA}

De cada um dos dez indivíduos (árvores) relacionados no Capítulo de Material, foi serrado um disco, a qualquer altura do tronco, com diâmetro aproximado de $45 \mathrm{~cm}$. Dele foram retirados, à distância de 5 a $10 \mathrm{~cm}$ de casca, dois blocos medindo aproximadamente 2 $\mathrm{cm}$ no sentido radial, $2 \mathrm{~cm}$ no sentido tangencial e $3 \mathrm{~cm}$ no sentido axial, os quais foram amolecidos em autoclave, durante cerca de trinta minutos, a uma pressão de 1,25 atmosferas, a $124^{\circ} \mathrm{C}$. Os cortes, obtidos no micrótomo AO Spencer 860 , nas espessuras de $28 \mu \mathrm{m}$, $20 \mu \mathrm{m}$ e $18 \mu \mathrm{m}$, respectivamente, para as seções transversal, radial e tangencial, foram corados com safranina e Fast green (conforme Johansen, 1940), sendo posteriormente montados em Permount.

Os valores dimensionais das fibras, bem como o comprimento dos elementos vasculares, foram tomados em material dissociado, em cujo preparo foi aplicada a mistura de Franklin (Jane, 1970) introduzindo-se, somente, alterações no modo de uso, necessárias às condições de laboratório: ácido acético p.a. e água oxigenada $20 \mathrm{vol}$., em partes iguais. Os fragmentos de madeira, imersos nessa mistura, foram colocados em frascos plásticos com tampa rosqueada e deixados em estufa regulada a $60^{\circ} \mathrm{C}$, durante 48 horas. A seguir, o material dissociado foi lavado e decantado por três vezes; finalmente, corado com safranina e montado em água.

No exame de elementos vasculares com placa de perfuração de tamanho muito reduzido e de difícil verificação, usou-se meio de montagem móvel, para o material dissociado, isto é, deixou-se líqüido farto entre lâmina e lamínula, de modo que, durante a observação microscópica, quando se comprimia a lamínula, levemente, com um estilete, os elementos giravam sobre o seu próprio eixo longitudinal, de forma a que toda a sua superfície pudesse ser explorada, com segurança.

As fotomicrografias foram obtidas com equipamento fotomicrográfico Olympus, modelo PM-7, adaptado ao microscópio Olympus modelo $\mathrm{FH}$, com filtro verde, com as combinações adequadas a cada caso e equipamento de contraste de fase, quando necessário.

\section{TERMINOLOGIA}

Para designar as estruturas anatômicas observadas no material em estudo e descre. vê-las, utilizaram-se a nomenclatura do Committee on Nomenclature International Associa-

(3) - Para avaliação da altura dos raios, foi adotado o seguinte sistema: foram aferidos 100 raios dizpsstos em imediata vizinhança e anotou-se simultaneamente, se cada um deles era fusionado ou não, pa:a o ten āo ćas porcentagens de ocorrência dos dois tipos. Completou-se, então, para 100, o número de aferiçōes de fusionados e de não fusionados, separadamente. De cada um destes corjuntos de 100 aferições, foram feitas as classificações de altura, dadas em porcentagens, e, também, extraídos os valores máximo e mínimo, e cá'culos das médias, desvio padrão e erro padrão, anotados na ficha biométrica. 
tion of Wood Anatomists (1964) e os esquemas da Comissão Pan Americana de Normas Tecnicas (COPANT, 1973). Para classificar diâmetros de elementos vasculares axiais não integrantes de vasos, aplicou-se a mesma tabela usada para os diâmetros dos vasos (COPANT, 1973).

Quando não foram encontradas na literatura designações adequadas para estruturas observadas, adotaram-se nomes, sempre que possível, análogos aos já conhecidos para fenômenos equivalentes. Tais termos acham-se relacionados no Glossário apresentado no Apêndice 9.2, acompanhados dos conceitos que Ihes foram atribuídos neste trabaiho.

\section{Resultados}

Em Bixa arborea Huber observa-se estratificação total do lenho, cuja estrutura, a seguir, se passa a analisar.

\section{vasOS}

São poucos e com diâmetros médios; $58,64 \%$ são geminados, $29,15 \%$ solitários, $11,53 \%$ múltiplos de três e $0,68 \%$ múltiplos de quatro; em disposição radial e também tangencial e irregular (Foto 1). É comum ocorrerem vasos com diâmetros muito pequenos e pequenos dispostos em agrupamentc irregu-

FICHA BIOMÉTRICA

\begin{tabular}{|c|c|c|c|c|c|c|c|c|}
\hline \multirow[b]{2}{*}{ Elementos Anatômicos } & \multirow{2}{*}{$\begin{array}{c}\mathrm{N} .^{\circ} \text { de } \\
\text { aferiçōes }\end{array}$} & \multirow{2}{*}{$\begin{array}{l}\text { Plano onde } \\
\text { se efetua } \\
\text { a aferição }\end{array}$} & \multirow{2}{*}{$\begin{array}{l}\text { Unidade } \\
\text { de } \\
\text { Medida }\end{array}$} & \multicolumn{2}{|r|}{ Valores } & \multicolumn{2}{|c|}{ Determinados } & \multirow[b]{2}{*}{$\begin{array}{l}\text { Erro } \\
\text { Padraáo }\end{array}$} \\
\hline & & & & Máximo & Mínimo & Média & $\begin{array}{l}\text { Desvio } \\
\text { Padrão }\end{array}$ & \\
\hline \multicolumn{9}{|l|}{ VASOS } \\
\hline Freqüência & 40 & Transversal & $\mathrm{n} . / \mathrm{mm}^{2}$ & 6,00 & 2,00 & 3,68 & 0,82 & 0,13 \\
\hline Diâmetro tangencial & 50 & Transversal & $\mu \mathrm{m}$ & 195,00 & 89,70 & 146,02 & 28,11 & 3,98 \\
\hline Comprimento dos elementos & 40 & Mat. dissoc. & $\mu \mathrm{m}$ & 628,00 & 344,30 & 426,46 & 45,32 & 7,17 \\
\hline Espessura da parede & 50 & Transversal & $\mu \mathrm{m}$ & 6,20 & 3,10 & 4,73 & 1,09 & 0,15 \\
\hline \multicolumn{9}{|l|}{ Diâmetro das pontuaçōes } \\
\hline Intervasculares & 20 & Tangencial & $\mu \mathrm{m}$ & 6,20 & 3,10 & 4,91 & 0,87 & 0,12 \\
\hline Parênquimo-vasculares & 20 & Tangencial & $\mu \mathrm{m}$ & 6,20 & 3,10 & 4,19 & 0,96 & 0,22 \\
\hline Rádio-vasculares & 20 & Radial & $\mu \mathrm{m}$ & 7,75 & 3,87 & 5,12 & 0,99 & 0,22 \\
\hline \multicolumn{9}{|l|}{ PARENQUIMA AXIAL } \\
\hline Altura da série & 20 & Tangencial & células & 5,00 & 2,00 & 3,60 & 0,66 & 0,02 \\
\hline Altura da série & 50 & Tangencial & $\mu \mathrm{m}$ & 594,70 & 297,35 & 420,79 & 67,30 & 15,05 \\
\hline Diâmetro tangencial da célula & 50 & Tangencial & $\mu \mathrm{m}$ & 31,20 & 19,50 & 24,88 & 3,30 & 0.47 \\
\hline \multicolumn{9}{|l|}{ PARENQUIMA RADIAL (RAIOS) } \\
\hline Freqũência & 200 & Tangencial & $\mathrm{n} . / \mathrm{mm}$ & 11,00 & 5,00 & 8,36 & 1,26 & 0,09 \\
\hline Altura dos não fusionados & 100 & Tangencial & células & 32,00 & 6,00 & 14,44 & 4,51 & 0,45 \\
\hline Altura dos não fusionados & 100 & Tangencial & $\mu \mathrm{m}$ & 782,50 & 219,10 & 411,60 & 133,70 & 13,37 \\
\hline Altura dos fusionados & 100 & Tangencial & células & 80,00 & 21,00 & 37,88 & 10,15 & 1,02 \\
\hline Altura dos fusionados & 100 & Tangencial & $\mu \mathrm{m}$ & 2363,15 & 610,35 & 1083,92 & 384,80 & 38,48 \\
\hline Largura & 100 & Tangencial & células & 3,00 & 1,00 & 2,15 & 0,48 & 0,05 \\
\hline Largura & 100 & Tangencial & $\mu \mathrm{m}$ & 46,80 & 15,60 & 28,39 & 7,80 & 0,78 \\
\hline \multicolumn{9}{|l|}{ FIBRAS } \\
\hline Comprimento & 200 & Mat. dissoc. & $\mu \mathrm{m}$ & 1868,30 & 719,90 & 1076,96 & 157,63 & 11,15 \\
\hline Diâmetro máximo & 100 & Mat. dissoc. & $\mu \mathrm{m}$ & 51,00 & 22,50 & 33,70 & 5.49 & 0,55 \\
\hline Diâmetro tangencial & 100 & Transversal & $\mu \mathrm{m}$ & 43,40 & 27,90 & 35,12 & 3,80 & 0,38 \\
\hline Largura do lume & 100 & Mat. dissoc. & $\mu \mathrm{m}$ & 45,00 & 15,50 & 27,75 & 5,59 & 0,56 \\
\hline Espessura da parede & 100 & Mat. dissoc. & $\mu \mathrm{m}$ & 4,50 & 1,55 & 2,98 & 0,77 & 0,08 \\
\hline
\end{tabular}

Estudo... 
lar, ou na imediata vizinhança dos vasos de diâmetros maiores. Os elementos vasculares são estratificados com os demais componentes do lenho; curtos, sem apêndices; os lumes, sem conteúdo visível; placa de perfuração simples e parcial, em área oblíqua ou horizontal (Fotos 12 e 16). Muitas vezes, são observados elementos irregulares, com perfuração em área oblíqua ou vertical.

O pontuado intervascular é alterno. As pontuações, com aréolas ovais ou circulares, são guarnecidas e possuem diâmetros pequenos; aberturas externas ovais, horizontais; aberturas internas lenticulares, horizontais, exclusas, raramente coalescentes duas a duas. Pontuações parênquimo e rádio-vasculares com a parte areolada semelhante às intervasculares, em disposição irregular.

\section{PARÊNQUIMA AXIAL}

É apotraqueal subagregado, em camadas celulares simples e tortuosas, de raio a raio, ocorrendo também, paratraqueal escasso. As células possuem paredes radiais estreitas, portanto numerosas pontuações, relativamen. te grandes, circulares, em alinhamento longitudinal. Na seção tangencial, as células apresentam forma retangular, com maior dimensão no sentido longitudinal e estão dispostas, em número de quatro, em séries estratificadas (Fotos 2 e 6 ).

\section{RAIOS}

São estratificados, todavia, com ocorrência de $40 \%$ de fusionados (Fotos 2 e 12); são pouco numerosos e numerosos; muito finos. $49,00 \%$ dos fusionados são muito baixos, $48,00 \%$ baixos e $3,00 \%$ medianos; os não fusionados apresentam-se $84,00 \%$ extremamente baixos e $16,00 \%$ muito baixos. São caracteristicamente multisseriados com duas e três células na largura, predominantemente bisseriados; entretanto, ocorrem também alguns unisseriados. O perênquima radial é constituído, na porção multisseriada, por fileiras de células horizontais e, nas extremidades unisse- riadas, por uma ou duas fileiras marginais de células quadradas, de paredes tangenciais estreitas; nos raios unisseriados, é composto de células horizontais e fileiras marginais simples, de células quadradas. Entre as células parenquimáticas, podem ocorrer elementos vasculares, cuja descrição se encontra no parágrafo 5.6 deste capítulo. Classificação conforme Kribs (Jane, 1970): Raios com tecido heterogêneo, tipo III a e $b$.

\section{FIBRAS}

São fibrotraqueóides, cujas pontuaçōes areoladas são guarnecidas. A aréola é oval; abertura interna inclusa, às vezes exclusa, lenticular. As pontuações são mais numerosas nas paredes radiais. Parede com estria espiralada fina. Classificação quanto ao comprimento: $61,50 \%$ são curtas, $36,50 \%$ muito curtas, $1,50 \%$ longas e $0,50 \%$ extremamente curtas; quanto à largura: $90,00 \%$ são médias, 6,00\% largas e 4,00\% estreitas; quanto à espessura relativa da parede: $80,00 \%$ são muito delgadas e $20,00 \%$ delgadas (Foto 16 ). Algumas vezes foram observados tipos de desenvolvimento anômalo, com extremidades bifurcarlas, ou com falta de uma ou de ambas as extremidades afiladas.

\section{ELEMENTOS TRAQUEAIS RADIAIS}

Nos raios de cinco das dez árvores de onde foram retiradas as amostras para estudo (Pessoal do LPF: 048; 112; 205; 265 e 472), observa-se a presença de células com padrão de elementos condutores de água no xilema (Fotos 1 a 8 e 16). São semelhantes a elementos vasculares, com forma irregular e variada, e dimensões aproximadas de $172 \mu \mathrm{m}$ de altura, quando dispostos entre as células procumbentes - elementos vasculares radiais procumbentes (Foto 3 ); sendo mais alto e curtos radialmente, quando localizados entre as célules quadradas - elementos vasculares radiais quadrados (Fotos 4 e 7). Ocorrem solitários ou em agrupamentos. Na seção transversal do lenho, suas presenças são evidenciadas por possuirem largura tangencial maior que as das 

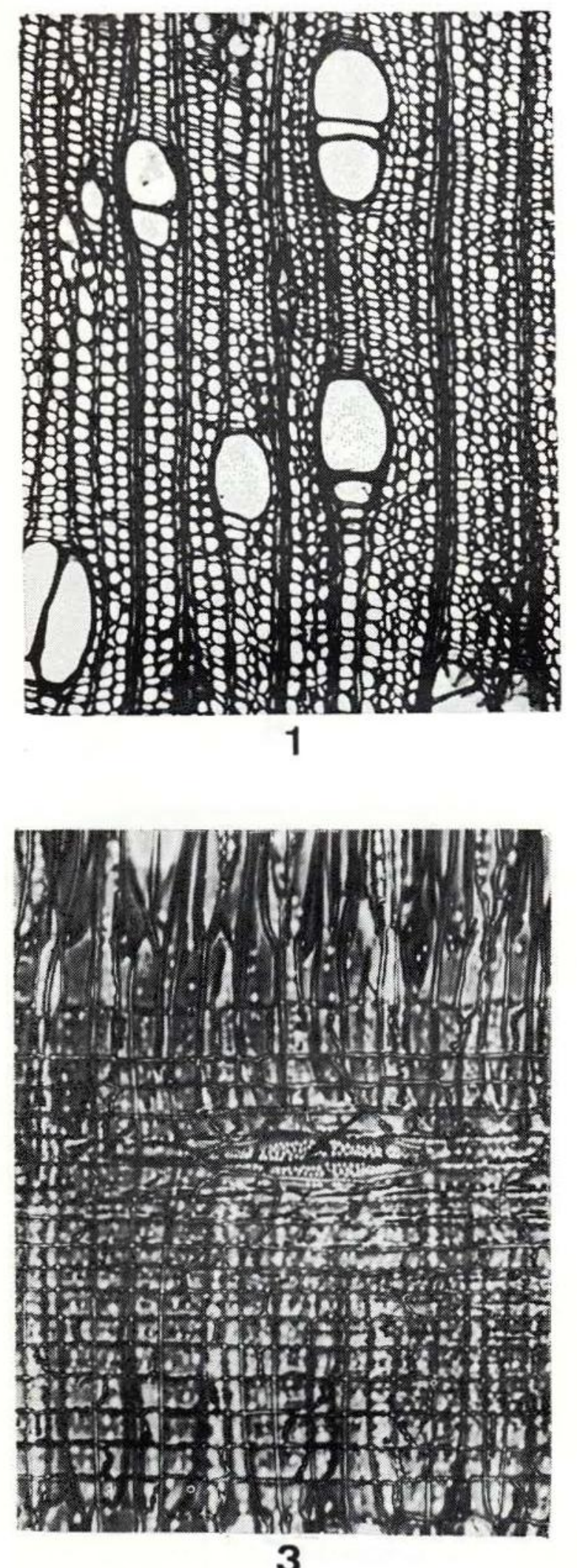
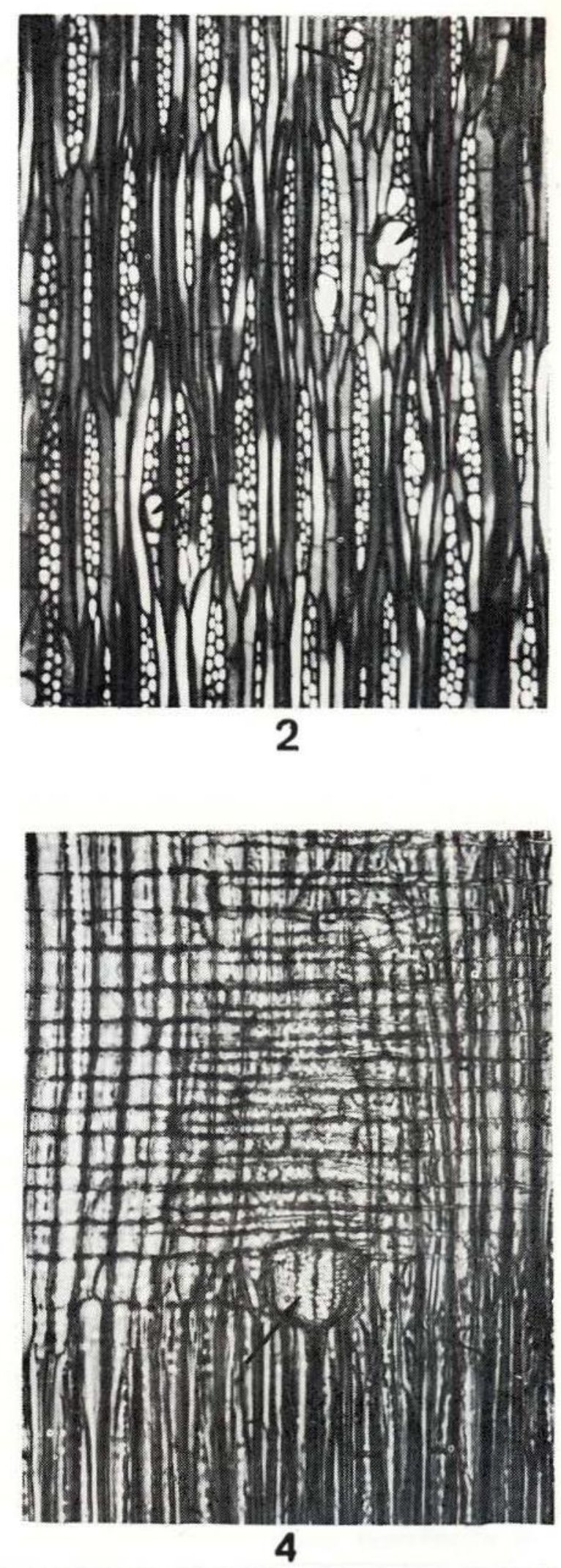

Foto 1 - Seção transversal $(x 80)$. Aspecto geral, mostrando, nos raios, áreas alargadas onde, habitualmente, ocorrem elementos vasculares radiais; Foto 2 - Seçăo tangencial $(x \quad 80)$. Aspecto geral, evidenciando presença de elementos vasculares radiais (as células radiais com diâmetros maiores); Foto 3 - Seção radial ( $x$ 200). Elemento vascular radial procumbente; Foto 4 - Seção radial $(x 200)$. Elemento vascular radial quadrado. 

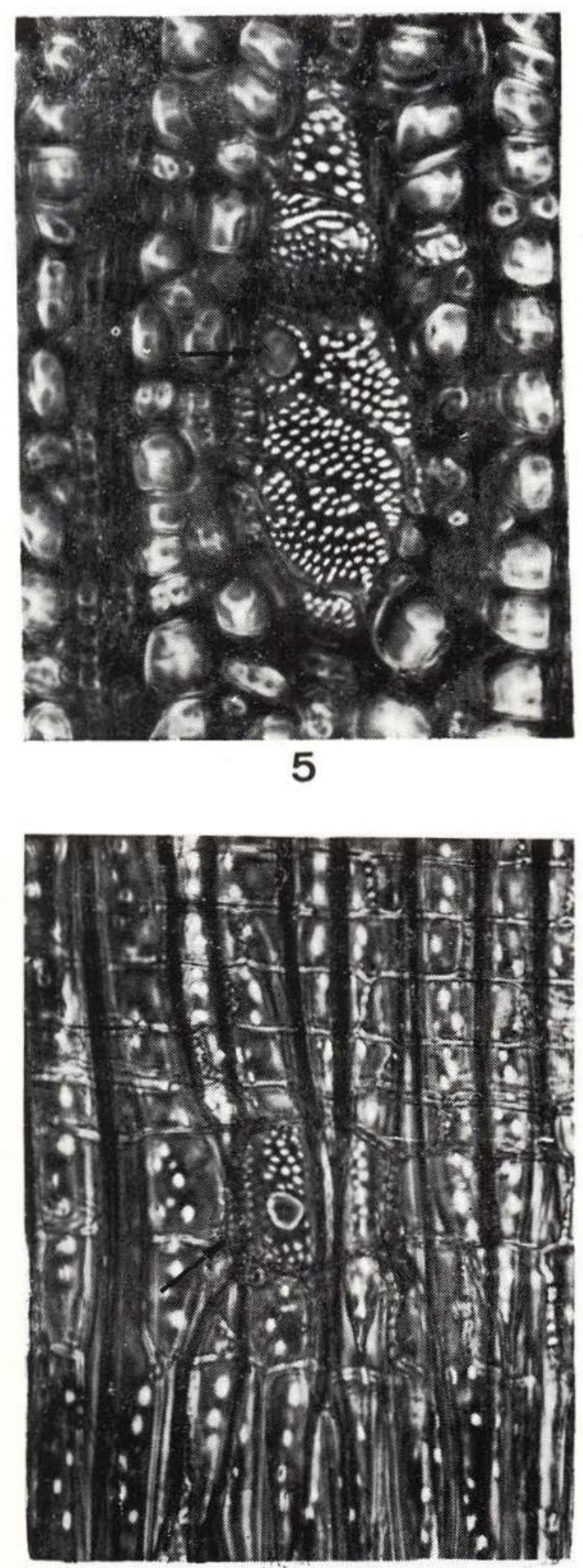

7
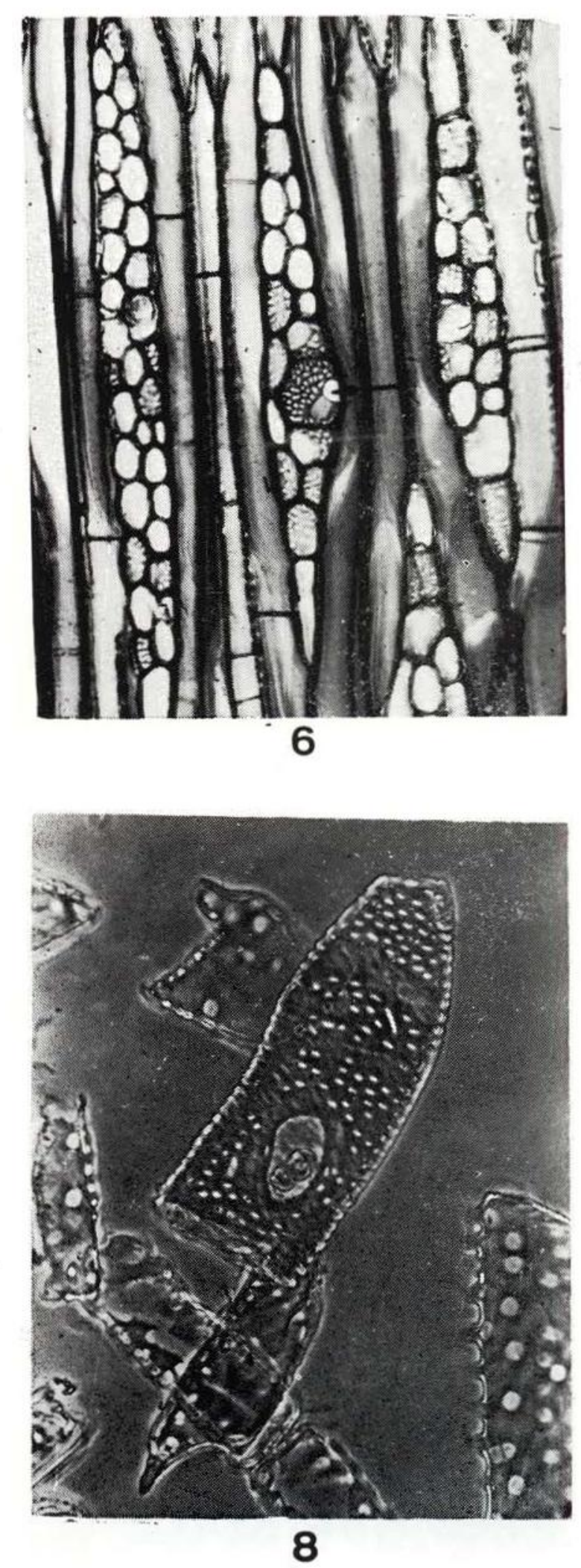

Foto 5 - Seção transversal ( $x$ 400). Elemento vascular radial, com vista frontal da parede, evidenciando pontuaçöes e placa de perfuração cega; Foto 6 - Seção tangencial $(x$ 250). Elemen o vascular radial, com pontuaçōes e placa de perfuração irregular; Foto 7 - Seção radial $(x 400)$. Elemento vascular radial quadrado, com placa de perfuração; Foto 8 - Material dissociado $(x 400)$. Células parenquimáticas e elemento vascular. 
outras células do raio (Foto 1), ou pela visão frontal da parede tangencial (Foto 5). Em seção tangencial (Fotos 2, 6 e 12), eles se destacam como elementos que possuem diâmetros maiores que os das células do parênquima radial. No material dissociado (Foto 16), podem comparar-se suas proporções com as dos elementos vasculares comuns, sem risco de confundi-los. Qualquer um dos tipos celulares existentes no lenho, pode ocorrer em sua imediata vizinhança. Possuem uma a três placas de perfuração simples, em qualquer disposição (Fotos 5, 6, 7 e 8); comumente apresentam placa de perfuração cega (Foto 5 ), ou irregular (Foto 6). Em aiguns casos, tem-se nítida impressão de que a parede não sofre solução de continuidade, apresentando, na área da placa, apenas, um adelgaçamento, mais acentuado, na linha de contorno do local onde deveria ocorrer a perfuração (Foto 7). O pontuado é alterno. As pontuações são areoladas e guarnecidas, com diâmetros pequenos; forma oval ou circular; possuem abertura externa oval, abertura interna lenticular, exclusa, poucas vezes coalescentes, e formam pares areolados com as pontuações de outros elementos vasculares ou de fibrotraqueóides, e pares semi-areolados com as pontuações simples das células parenquimáticas. Também podem ocorrer pontuações cegas.

\section{ELEMENTOS VASCULARES AXIAIS NÃO INTEGRANTES DE VASO}

Elementos vasculares fibriformes (Fotos 9,10 e 13): ocorrem, com relativa freqüência, dispostos lado a lado, em pequenos agrupamentos, ou solitários, com altura equiparável à dos demais elementos estratificados, com diâmetro muito pequenos a extremamente pequenos. As extremidades afiladas ou arredondadas, contatam com séries do parênquima axial, com fibrotraqueóides, ou com outros elementos fibriformes. Nos cortes transversais, os agrupamentos são observados ora isolados entre as fibras, ora junto a raios, na imediata vizinhẩnça de células do parênquima radial, ou de elementos vasculares radiais. Podem apresentar uma a três placas de perfuração simples, em área vertical; às vezes são cegas, em relação ao elemento contíguo. As pontuações são semelhantes às dos elementos vasculares de localização normal, em disposição e forma; formam pares areolados e semiareolados, conforme estejam, respectivamente, na imediata vizinhança de elementos vasculares ou fibrotraqueóides, ou de células parenquimáticas. Também ocorrem pontuações cegas.

Elementos vasculares vasicêntricos (Fotos 11, 12, 14 e 15): Podem ser observados ao lado de linhas vasculares definidas; têm diâmetros muito pequenos a extremamente pequenos (Foto 11), e comprimento equiparável ao dos elementos vasculares normais (Foto 12). Além dos vasos, podem estar em contato com elementos vasculares radiais (Foto 14) ou com qualquer um dos outros tipos celulares existentes no lenho. As paredes transversais, geralmente, contatam com séries do parênquima axial. As placas de perfuração (Foto 14) e as pontuações (Foto 11, 14 e 15), quanto à disposição e forma, são como as descritas para elementos vasculares radiais.

Elementos vasculares disjuntivos: observados com muito pouca freqüência, têm forma irregular e estão ligados ao vaso apenas por uma placa de perfuração localizada em prolongamento tubular curto. Entre seu corpo e o do elemento vascular integrante do vaso, ocorre série de parênquima axial ou raio. Os pontuações são como as descritas para os outros elementos vasculares.

\section{DISCUSSÃo}

Em seu aspecto geral, o lenho de Bixa arborea Huber se assemelha bastante ao de $B$. orellana L. (Metcalfe \& Chalk, 1950). Todavia, a presença de elementos vasculares com localização anormal marca a grande diferença entre ambas. Com relação a esses elementos observados, não se encontrou na literatura referência a fato igual, embora ocorrências de elementos traqueais radiais já tenham sido registrados anteriormente: Jane (1970), embora não invalidando o conceito estabelecido, de que os raios das Angiospermae são exclusiva- 

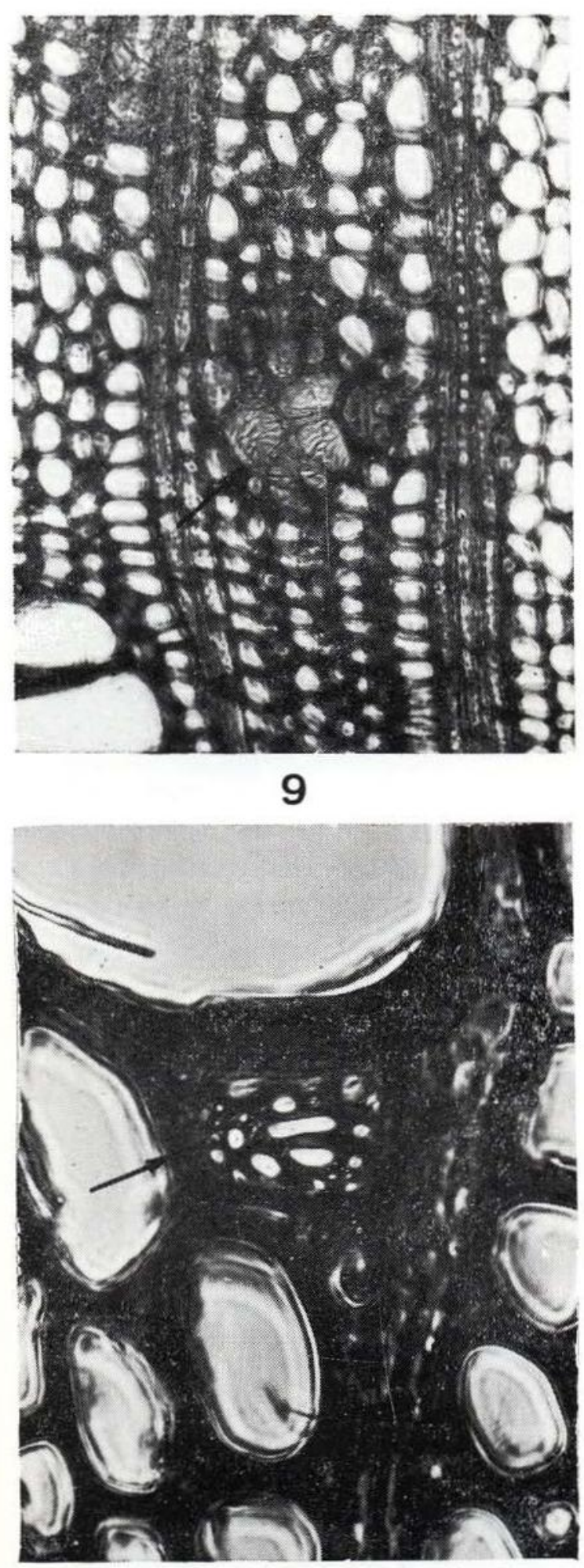

11

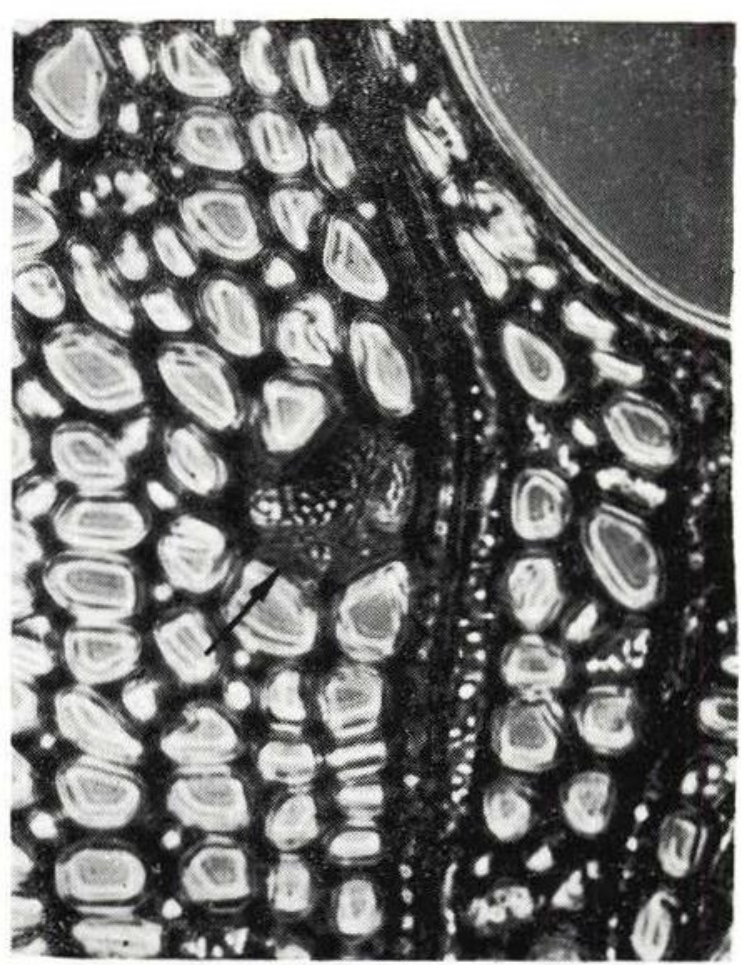

10

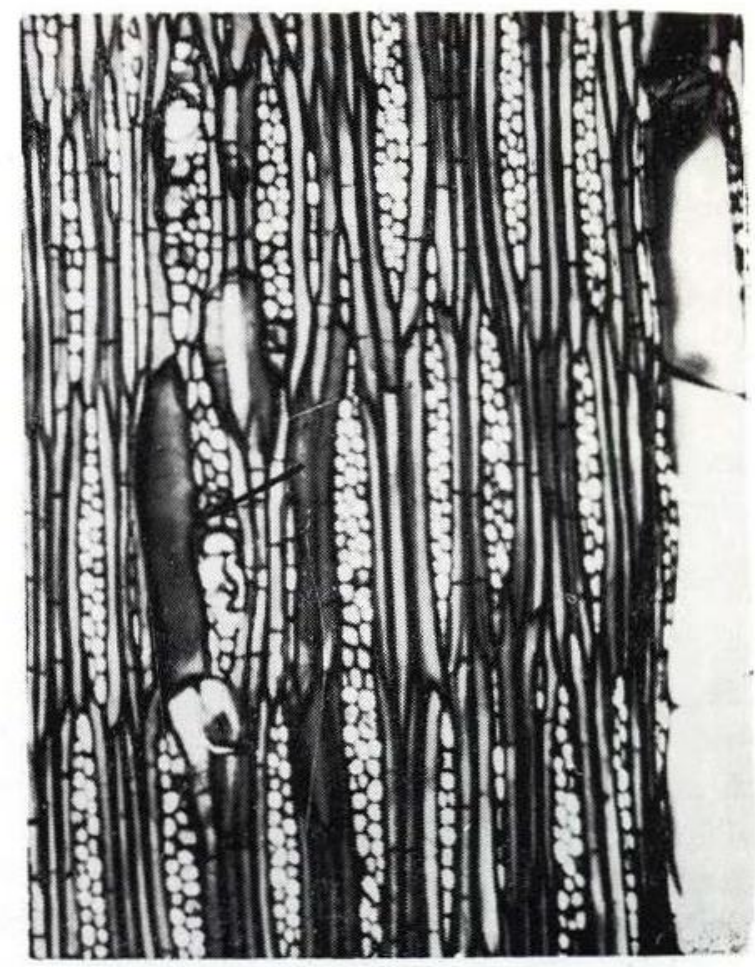

12

Foto 9 - Seção transversal ( $x$ 250). Agrupamento de elementos vasculares fibriformes, localizado entre fibras; Foto 10 - Seção transversal $(x$ 400). Agrupamento de elementos vasculares fibriformes, localizado na imediata vizinhança de un raio; Foto 11 - Seção transversal ( $x$ 1.200). Elemento vascular vasicêntrico; Foto 12 - Seção tangencial $(x 80)$. Elemento vascular axial não integrante de linha vascular definida localizado na imediata vizinhança de elementos vasculares radiais. 


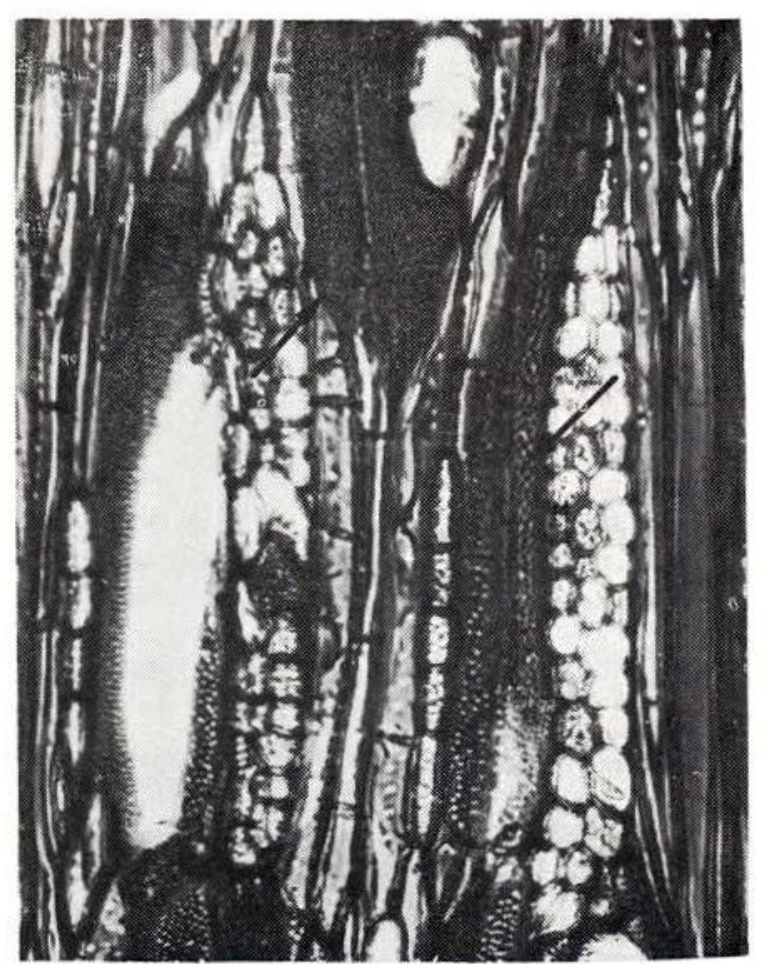

13

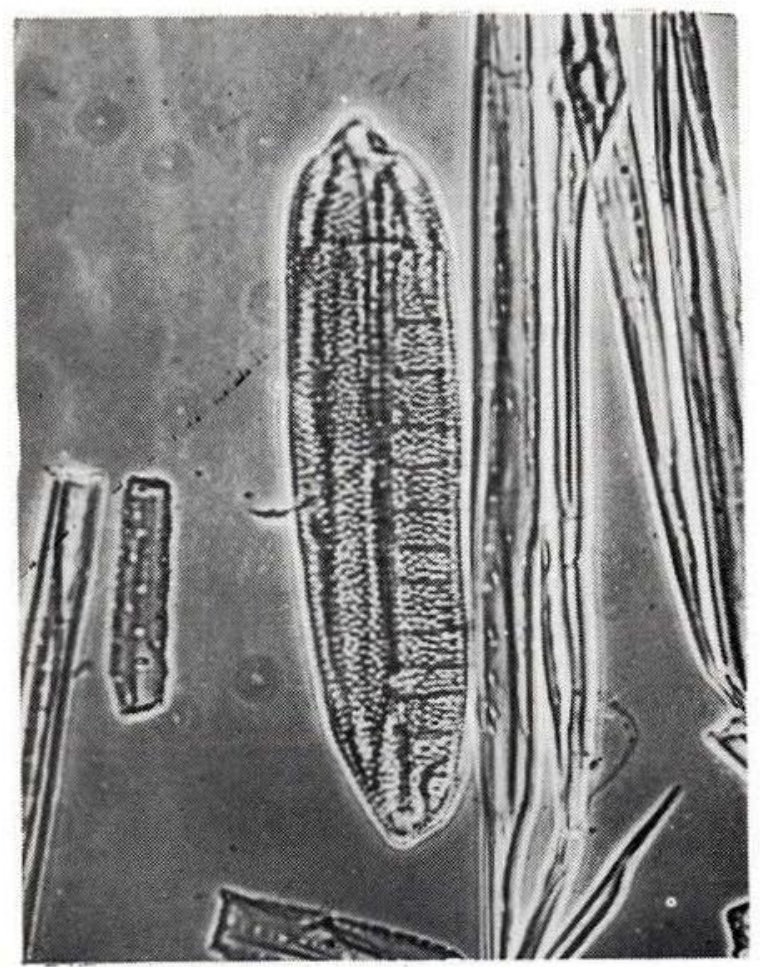

15

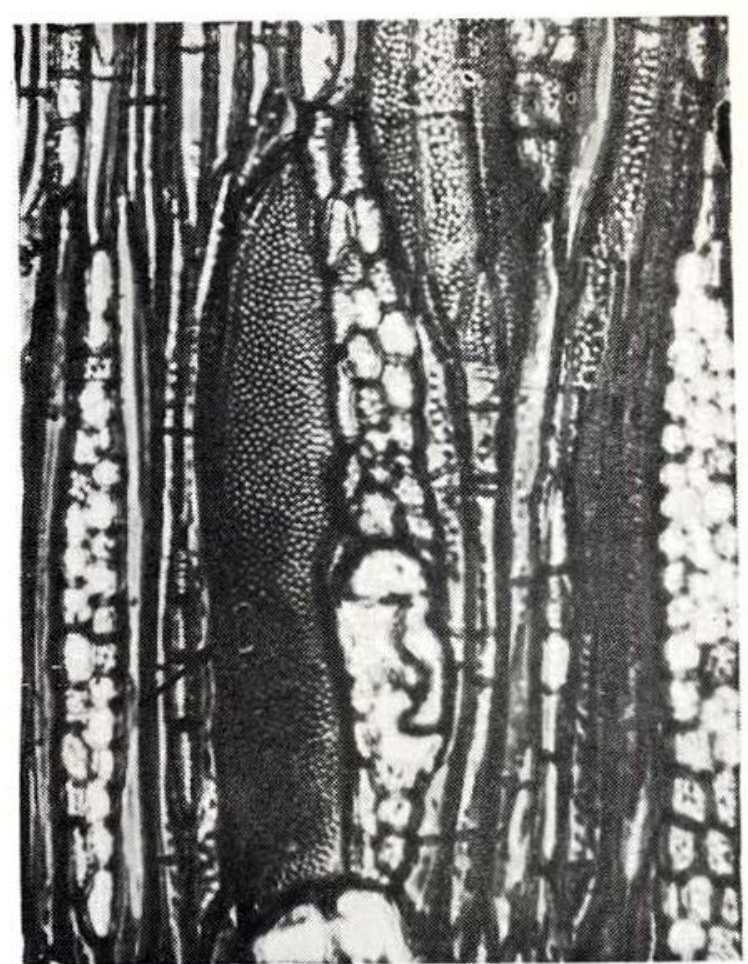

14

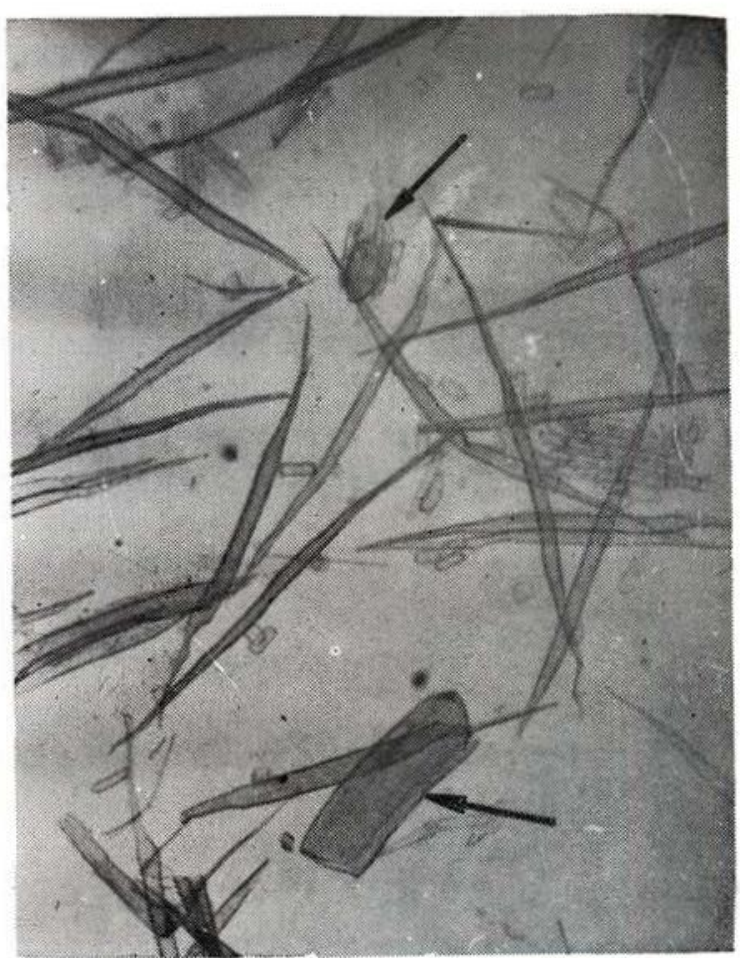

16

Foto 13 - Seção tangencial ( $x$ 200). Elementos vasculares fibriformes; Foto $14-$ Seção tangencial ( $x$ 200). Elemento vascưlar axial não integrante de linha vascular definida, evidenciando uma placa de perfuração; Foto 15 - Material dissociado ( $x$ 200); Foto 16 - Material dissociado ( $x$ 45), evidenciando um elemento vascular de padrão normal $e$ um elemento vascular radial, de dimensões bem menores, ainda ligado às células parenquimáticas radiais. 
mente parenquimatosos, relata a presença de traqueóides radiais em Quercus alba L. e em Gonioma kamassi E. Meyer e de fibrotraqueóides radiais em Neesia altissima Blume, e o que se verificou em $B$. arborea Huber constitui mais uma dessas raríssimas exceções.

\section{CONCLusõ̃es}

O material examinado apresentou, basicamente, a mesma estrutura, sendo que em $50 \%$ dos indivíduos foi confirmada a presença de elementos vasculares radiais. Como não se têm informações sobre as alturas de tronco de onde foram retiradas as amostras, é impossível saber se a verificação do fenômeno apenas naqueles indivíduos, se deve às diferentes alturas de procedência das amostras, ou se, realmente, o mesmo não teria ocorrido em $50 \%$ das árvores, podendo, nesse caso, tratarse de um caráter recessivo.

As observações feitas do contato entre os diversos tipos de elementos vasculares existentes no lenho estudado, deixam supor que poderá haver uma interligação mais direta en. tre vasos e raios.

O que se observou em Bixa arborea Huber pode ter conotação com o grau evolutivo da espécie e pode ser de importância para o entendimento de problemas relacionados com a evolução e filogenia da família Bixaceae, o que justificaria proceder-se ao estudo de todas as suas espécies, utilizando-se amostragem mais adequada.

\section{Agradecimentos}

Aos Drs. Harry J. van der Slooten e Cleber Delano José Lisboa, pelo apoio técnico administrativo; aos botânicos Dr. João Murça Pires e William Rodrigues, pela identificação botânicas dos especimes analisados; à bióloga Vera Rauber Coradin, pelo trabalho de revisão; à bióloga Irene da Costa Alvarenga Mendes. pelo apoiơ prestado e obtenção das fotos 6 , 8 e 9; aos auxiliares técnicos José Maria Rodrigues Camargos e Zenon Lopes de Sousa, pelo preparo de amostras e microtécnica; ao Senhor Nestor B. Lima, pela execução de serviços fotográficos; à Srta. Regina Célia de Moraes Bello, pelos trabalhos datilográficos; e aos demais colegas do LPF, por toda colaboração prestada no desenvoivimento e publicação deste trabalho.

\section{SUMMARY}

Microscopic analysis on wood samples of Bixa arborea Huber, a Bixaceae, showed the occurrence of a not exclusively parenchymatous radial structure. Such phenomenon is equivalent to only three other cases recorded in the revised literature, for Angiospermae species.

This research has also evidenced the presence of axial vessel members not forming part of definite axial rows.

The present work documents and describes the xylem of this species emphasizing the anomalous structures observed.

\section{REFERENCIAS BIBLIOGRÁFICAS}

COMMITTEE ON NOMENCLATURE INTERNATIONAL ASSOCIATION OF WOOD ANATOMISTS

1964 - Multilingual glossary of terms used of wood Anatomists. 3 ed. Verlag, Konkordia Winterthur, 46p.

COMISSÃO PAN-AMERICANA DE NORMAS TÉCNICAS

1973 - Descrição macroscópica, microscópica e geral da madeira - esquema I de recomendação. Colômbia, 19p. (COPANT 30).

ESAU, $K$.

1972 - Anatomia vegetal. Trad. de José Pons Rosell. 2 ed rev. Barcelona, Omega, 779p.

1974 - Anatomia das plantas com sementes. Trad. de Berta Lange de Morretes. São Paulo, Edgard Elücher, 293p.

JANE, F.W.

1970 - The struture of wood. 2 ed. London, Adam \& Charles Black, 478p.

JOHANSEN, D.A.

1946 - Plant microtechnique. 2 ed. New Delhi, 523p.

METCALFE, C.K. \& CHALK, L.

1950 - Anatomy of the Dicotyledons. Oxford, Clarendon Press. $2 \mathrm{v}$.

(Aceito para publicação em 25/01/82) 


\section{GLOSSÁRIO}

Elementos traqueais radiais: designação para referência conjunta a tipos de células radiais com o mesmo padrão das principais células condutoras de água no xilema, essencialmente, os elementos vasculares e as traqueóides.

Traqueóide radial: traqueóide integrando um raio (Committee on Nomenclature International Association of Wood Anatomists 1964).

Elemento vascular radial: elemento vascular que integra um raio:

- procumbente: elemento vascular radial localizado em fileira de células procumbentes.

- quadrado: elemento vascular radial localizado em fileira de células quadradas.

Elementos vasculares axiais não integrante de vaso: expressão usada para referência conjunta a tipos de elementos vasculares axiais dispostos fora de linhas vasculares definidas.
Elemento vascular vasicêntrico: elemento vascular situado na imediata vizinhança de um vaso e que não é parte integrante de uma linha vascular definida.

Elemento vascular fibriforme: elemento vascular de diâmetro relativamente pequeno, apresentando semelhança com fibrotraqueóide. (Committee on Nomenclature International Association of Wood Anatomists 1964).

Elemento vascular disjuntivo: elemento vascular desarticulado do vaso e a ele ligado por placa de perfuração pequena, localizada em um prolongamento tubular.

Placa de perfuração cega: diz-se da placa de perfuração em que a solução de continuidade da parede de um elemento vascular está em contato com uma área de parede da célula contígua, em que não há solução de continuidade.

Placa de perfuração irregular: diz-se da placa de perfuração em que não há perfeita correspondência de forma e tamanho entre as soluções de continuidade das paredes dos dois elementos vasculares contíguos. 